\title{
Comparing microphysical/dynamical outputs by different cloud resolving models: impact on passive microwave precipitation retrieval from satellite
}

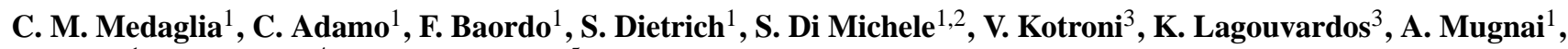 \\ S. Pinori ${ }^{1}$, E. A. Smith ${ }^{4}$, and G. J. Tripoli ${ }^{5}$ \\ ${ }^{1}$ Istituto di Scienze dell' Atmosfera e del Clima, Consiglio Nazionale delle Ricerche, Roma, Italy \\ ${ }^{2}$ European Centre for Medium-Range Weather Forecasts, Reading, UK \\ ${ }^{3}$ Institute of Environmental Research, National Observatory of Athens, Athens, Greece \\ ${ }^{4}$ Goddard Space Flight Center, National Aeronautics and Space Administration, Greenbelt, Maryland, USA \\ ${ }^{5}$ Department of Atmospheric and Oceanic Sciences, University of Wisconsin, Madison, Wisconsin, USA
}

Received: 28 February 2005 - Accepted: 18 May 2005 - Published: 7 June 2005

\begin{abstract}
Mesoscale cloud resolving models (CRM's) are often utilized to generate consistent descriptions of the microphysical structure of precipitating clouds, which are then used by physically-based algorithms for retrieving precipitation from satellite-borne microwave radiometers. However, in principle, the simulated upwelling brightness temperatures $\left(\mathrm{T}_{\mathrm{B}}\right.$ 's) and derived precipitation retrievals generated by means of different CRM's with different microphysical assumptions, may be significantly different even when the models simulate well the storm dynamical and rainfall characteristics.

In this paper, we investigate this issue for two well-known models having different treatment of the bulk microphysics, i.e. the UW-NMS and the MM5. To this end, the models are used to simulate the same 24-26 November 2002 floodproducing storm over northern Italy. The model outputs that best reproduce the structure of the storm, as it was observed by the Advanced Microwave Scanning Radiometer (AMSR) onboard the EOS-Aqua satellite, have been used in order to compute the upwelling $\mathrm{T}_{B}$ 's. Then, these $\mathrm{T}_{\mathrm{B}}$ 's have been utilized for retrieving the precipitation fields from the AMSR observations. Finally, these results are compared in order to provide an indication of the CRM-effect on precipitation retrieval.
\end{abstract}

\section{Introduction}

Physically-based passive-microwave precipitation retrieval algorithms make use of cloud radiation databases (CRD's) that are composed of thousands of detailed microphysical

Correspondence to: C. M. Medaglia

(c.medaglia@isac.cnr.it) cloud profiles, obtained from cloud resolving model (CRM) simulations, coupled with the corresponding brightness temperatures $\left(\mathrm{T}_{\mathrm{B}}\right.$ 's), calculated by applying radiative transfer (RT) schemes to the CRM outputs (e.g., Smith et al., 1994). As a consequence, the accuracy of precipitation retrievals may be very much dependent on the CRM skill to provide a consistent and realistic description of the microphysical structure of precipitating clouds - besides reproducing their dynamical behavior and cumulated rainfall.

On the other hand, CRM's adopt bulk microphysical schemes that provide a rather crude representation of the very complex and storm-dependent microphysical characteristics of the iced and melted hydrometeors. Thus, it would be important to perform sensitivity studies aiming at assessing the impact of different CRM microphysical schemes and simulations on the generated CRD's and on the derived retrievals. This problem, however, has been largely overlooked in the past - even though some authors (e.g., Panegrossi et al., 1998) have performed comparative analyses of cloudradiation features generated by different storm simulations.

In this paper, we extend a previous work by Dietrich et al. (2003) who made a preliminary comparison of the microphysics and the microwave signatures of two simulations of the 24-26 November 2002 flood-producing storm over Northern Italy, that were performed by the University of Wisconsin - Non-hydrostatic Modeling System (UW-NMS) (Tripoli, 1992) and by the Penn State University/NCAR Mesoscale Model (MM5) (Dudhia, 1993).

\section{Description of the heavy-precipitation event}

On 24 November 2002, at 00:00 UTC, the northern part of Italy was under the influence of a diffluent trough with its axis spanning from Ireland trough western Spain and 


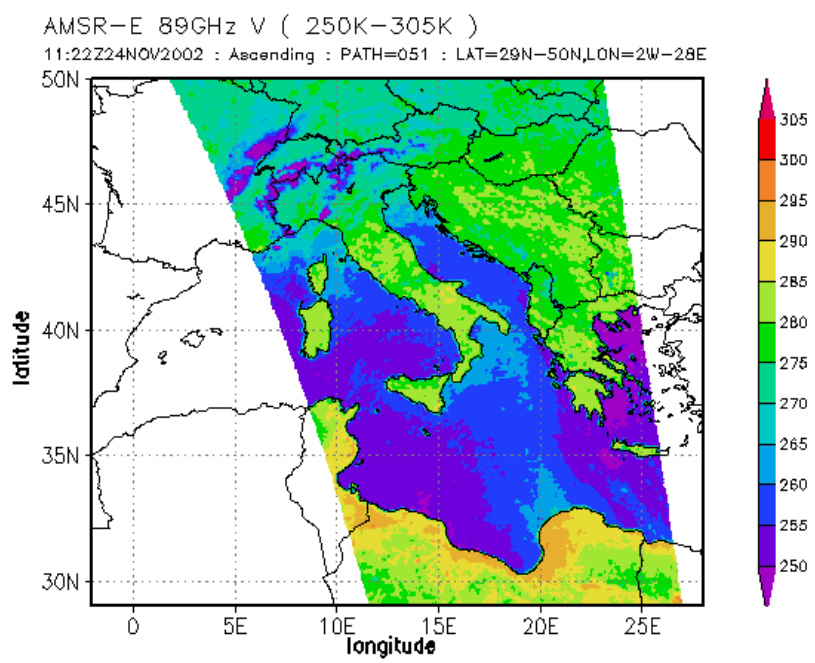

Fig. 1. AMSR-E $89 \mathrm{GHz}$ upwelling $\mathrm{T}_{\mathrm{B}}$ 's at 11:22 UTC, 24 November 2002 .

Portugal. At low levels warm and humid air originating from the Mediterranean area was driven northward towards the Alps where it met cold and dry air originating from the eastern Atlantic. An intense Sirocco wind was present throughout the Italian peninsula, raising surface temperatures up to $25^{\circ} \mathrm{C}$ in northwest Sardinia. Rainfall began on 24 November in the western part of the Alps, over the Liguria and Lombardia regions. On 25 November, the storm system moved towards the eastern Italian Alps, spawning intense thunderstorms, and in some cases hail, over the Lombardia and Friuli regions. Heavy rains continued until 26 November when precipitation ended in response to subsidence from a highpressure system centered over Eastern Europe. As described by Tripoli et al. (2001), heavy precipitation in these areas results as the Sirocco wind is channeled around the topography surrounding the Tyrrhenian Sea.

The present study focuses on the late morning - early afternoon of 24 November, as there was an AMSR-E overpass at 11:22 UTC over the Italian peninsula (Fig. 1).

\section{Cloud model simulations}

The 24-26 November 2002 flood-producing storm over Northern Italy, has been simulated by two models: the UWNMS and the MM5. These are two well-known threedimensional time-dependent explicit non-hydrostatic cloud resolving models, that have different treatments of the bulk microphysics.

The UW-NMS model employs a two-way multiple nested grid system that allows any nest to move along a specified trajectory or to move with the surface pressure minimum. The UW-NMS generalized bulk microphysics scheme predicts the mixing ratios of six different hydrometeor categories (cloud droplets, rain drops, graupel particles, pristine ice crystals, snowflakes, and ice aggregates). To simulate this event, three nested grids were used: grid 1 (with $37.5 \mathrm{~km}$ resolution) covering a large region spanning much of Europe, the Mediterranean and North Africa; grid $2(9.4 \mathrm{~km}$ resolution) covering North-Central Italy and the Southern regions of Germany and France; and grid 3 (3.1 km resolution) covering Northern Italy. Grid 3 uses $141 \times 261$ horizontal grid points and 35 vertical levels (up to $18 \mathrm{~km}$ ). The NCEP Global Forecasting System (GFS) gridded analysis fields at 00:00 UTC, 24 November 2002 have been used to initialize the model and to nudge the boundaries of grid 1 during the simulation period. The simulations for all three grids lasted for $72 \mathrm{~h}$.

The MM5 model (Version 3) is a non-hydrostatic primitive equation model using terrain-following coordinates. Several physical parameterization schemes are available in the model for the boundary layer, the microphysics and the cumulus convection. For the simulations performed for this study, the same schemes used by Kotroni and Lagouvardos (2001). have been adopted. In particular, the mixing ratios of five different hydrometeors (cloud droplets, rain drops, graupel particles, pristine ice crystals, and snowflakes) are predicted. To simulate this event, three nested grids were used that cover roughly the same regions than the corresponding grids of the UW-NMS model, however, with a different resolution - i.e., $24 \mathrm{~km}$ resolution for grid 1; $8 \mathrm{~km}$ resolution for grid 2; and $2 \mathrm{~km}$ resolution for grid 3 . Grid 3 uses $250 \times 250$ horizontal grid points and 30 vertical levels (up to $16 \mathrm{~km}$ ). Again, the NCEP GFS gridded analysis fields at 00:00 UTC, 24 November 2002 have been used to initialize the model and to nudge the boundaries of grid 1 during the simulation period. The simulations lasted for $72 \mathrm{~h}$ for all three grids.

For the purposes of this study, the model outputs from the inner grid of both models have been analyzed in order to select those outputs that best reproduce the storm structure as observed by the AMSR-E overpass (Fig. 1). Based on this criterion, the model output of UW-NMS at 15:00 UTC, 24 November 2002 and the model output of MM5 at 13:00 UTC, 24 November 2002 are used in the rest of this study.

Figure 2 shows the columnar equivalent water contents (CWC's) for selected hydrometeor species as a function of rainfall rate, at the selected times from both model simulations. The different bulk microphysics schemes adopted by the two models produce remarkable differences in the hydrometeor CWC's despite the overall similarity of the rainfall fields. The rain CWC's generated by the UW-NMS are considerably higher than those for the MM5. The ice CWC's show even larger differences: the MM5 produces many more hard-ice (graupel) particles than the UW-NMS, which, in turn, produces much more soft-ice (snowflakes + ice aggregates) than the MM5. Noteworthy, while there is a considerable dispersion (not shown) around the average values shown in this figure, these results provide useful information for our following analyses on the simulated TB's and the resulting rainfall retrievals.

Finally, we mention that the average surface temperature for the MM5 simulation is constantly lower (about 2$3 \mathrm{~K}$ ) than for the UW-NMS simulation, while the UW-NMS 

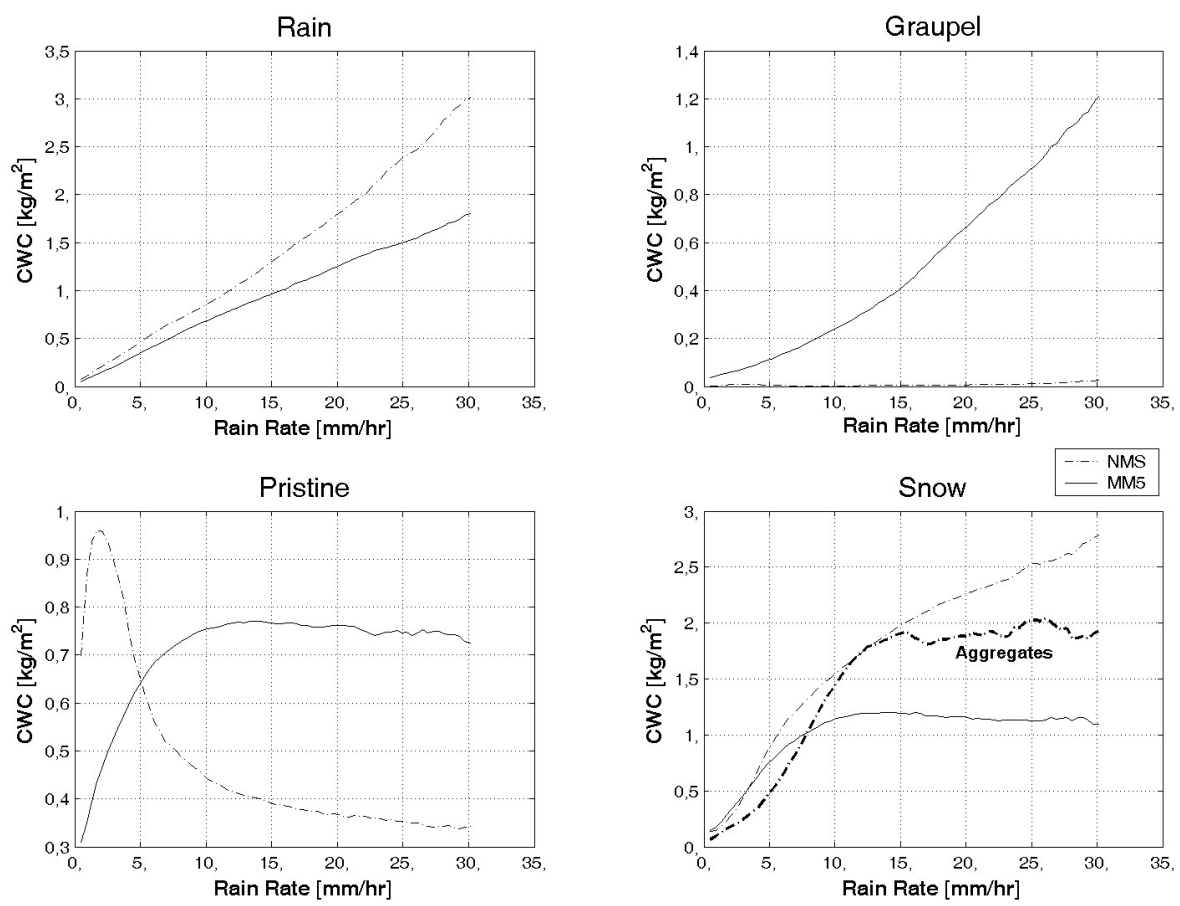

Fig. 2. Average CWC's of the indicated hydrometeor species as a function of rain rate for the inner grids of the UW-NMS (dashed) and MM5 (solid) simulations at the selected times. Note that in the bottom right panel (snow) the UW-NMS aggregates are also shown (heavy dashed).

simulation is significantly more humid than the MM5 simulation. The average columnar water vapor content is always higher for the UW-NMS simulation and, in contrast to the MM5 simulation, it increases monotonically with rain rate.

\section{Simulated brightness temperatures}

In order to generate the cloud-radiation databases to be used for retrieving precipitation from the AMSR observations of Fig. 1, we have simulated the AMSR upwelling brightness temperatures by applying a radiative transfer code to the microphysical outputs of the UW-NMS and MM5 simulations presented in Sect. 3. Figure 3 shows the average upwelling $\mathrm{T}_{\mathrm{B}}$ 's at four AMSR frequencies $(18.7,23.8,36.5$, and $89 \mathrm{GHz}$ ) as a function of rain rate for the UW-NMS and MM5 simulations.

At the two lower frequencies, the upwelling $\mathrm{T}_{\mathrm{B}}$ 's are basically responsive to surface emission, (cloud + rain) liquid water emission and water vapor emission. At $18.7 \mathrm{GHz}$, the UW-NMS $\mathrm{T}_{\mathrm{B}}$ 's for low rain rates are a few degrees higher than those for the MM5, because of higher surface temperature and columnar water vapor content. As rain rate increases, the MM5 $\mathrm{T}_{\mathrm{B}}$ 's first increase because of increasing rain liquid water emission, then (around $10 \mathrm{~mm} / \mathrm{hr}$ ) level off because of signal saturation, and finally (for rain rates larger than about $20 \mathrm{~mm} / \mathrm{hr}$ ) decrease because emission occurs at increasingly high altitudes (and therefore at increasingly cold temperatures) due to increasing atmospheric optical depth. A similar behavior is observed for the UW-NMS
$\mathrm{T}_{\mathrm{B}}$ 's; however, in this case signal saturation occurs at lower rain rates while the subsequent decrease is faster because of larger rain CWC's and water vapor amounts. The behavior of the $23.8 \mathrm{GHz} \mathrm{T}_{\mathrm{B}}$ 's can be explained in a quite similar way and differs from the $18.7 \mathrm{GHz}$ case because of increased water vapor absorption. At the two higher frequencies, the upwelling $T_{B}$ 's are responsive to ice scattering, besides emission and scattering by liquid water and water vapor emission. That is why the upwelling $\mathrm{T}_{\mathrm{B}}$ 's steadily decrease as rain rate increases - i.e., as rain and ice CWC's increase. These $T_{B}$ depressions span a range of $15-20 \mathrm{~K}$ at $36.5 \mathrm{GHz}$, which increases up to $60-70 \mathrm{~K}$ at $89 \mathrm{GHz}$ due to the fact that scattering effects increase with frequency. The MM5 upwelling $\mathrm{T}_{\mathrm{B}}$ 's at $36.5 \mathrm{GHz}$ are constantly lower $(2-5 \mathrm{~K})$ than for the UW-NMS simulation because ice scattering is mainly due to the denser graupel particles, which are basically present only in the MM5 simulation. In contrast, the UW-NMS upwelling $\mathrm{T}_{\mathrm{B}}$ 's at $89 \mathrm{GHz}$, become increasingly lower (up to $10 \mathrm{~K}$ ) than for the MM5 above about $10 \mathrm{~mm} / \mathrm{hr}$ soft-ice because of the increasingly larger scattering effect due to snowflakes and ice aggregates.

\section{Precipitation retrievals}

The simulated upwelling $\mathrm{T}_{\mathrm{B}}$ 's described in Section 4 have been used to generate two different CRD's that correspond to the two simulations. Then, these two CRD's have been utilized within the algorithm developed by Di Michele et al. (2003, 2005 - see also Mugnai et al., 2001) to perform two 

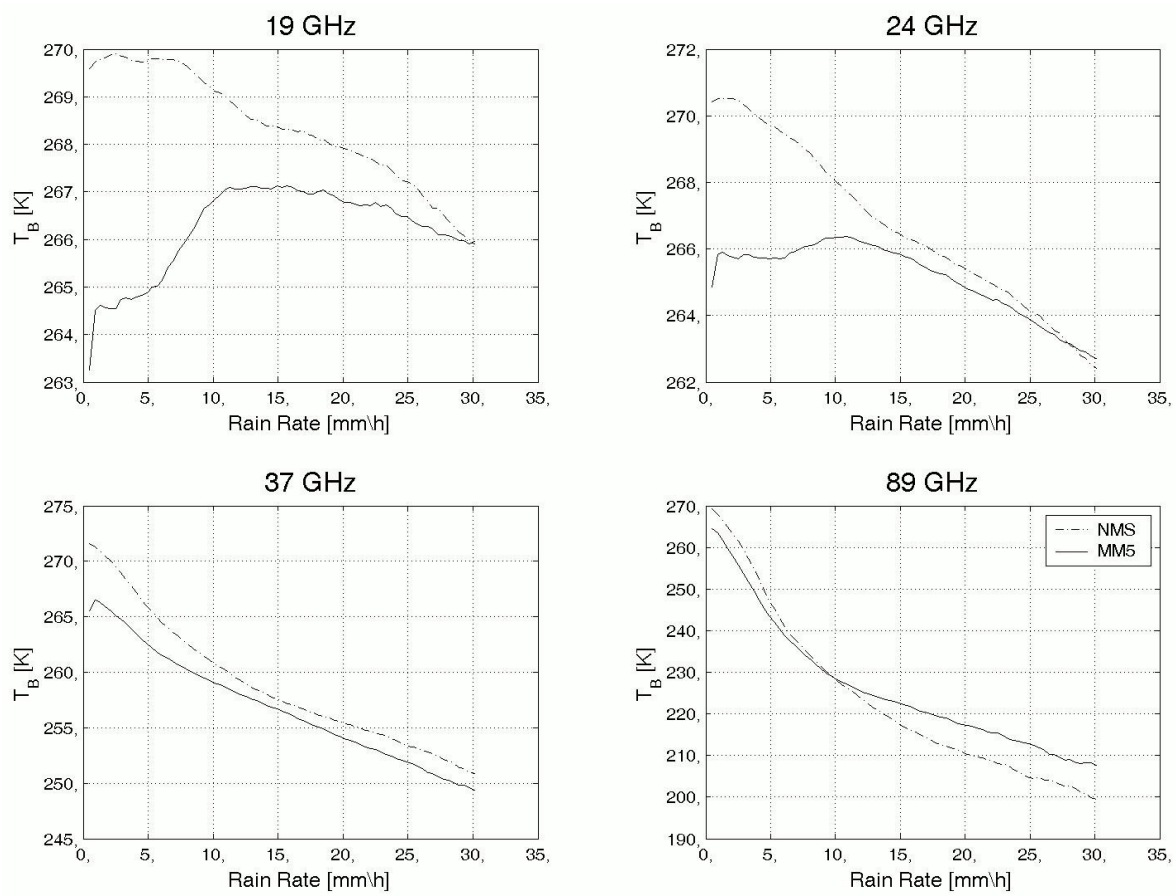

Fig. 3. Average upwelling $T_{B}$ 's at four AMSR frequencies $(18.7,23.8,36.5$, and $89 \mathrm{GHz})$ as a function of rain rate for the inner grids of the UW-NMS (dashed) and MM5 (solid) simulations.

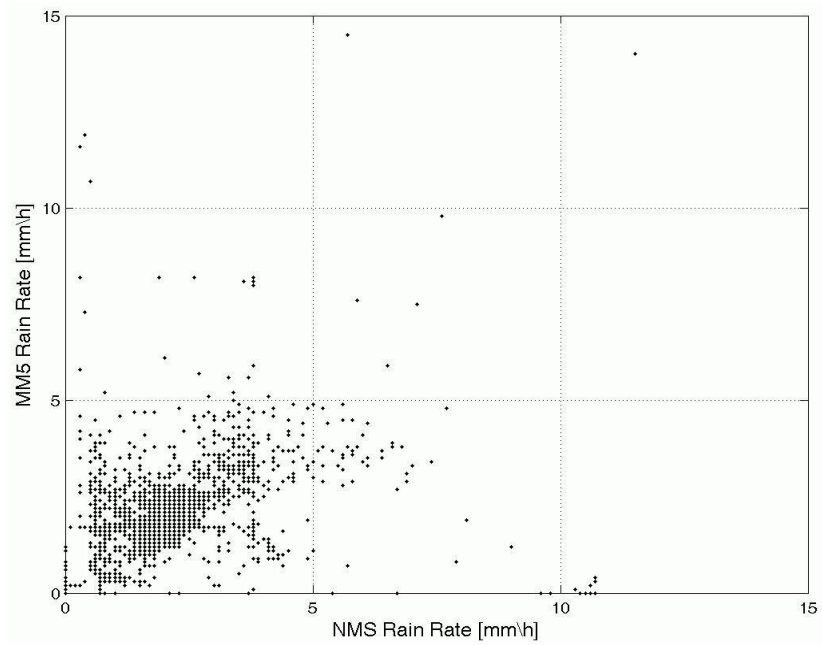

Fig. 4. Rainfall retrievals based on the MM5 CRD vs. corresponding retrievals based on the UW-NMS CRD.

different rainfall retrievals from the AMSR observations of Sect. 2. Figure 4 is a scatterplot of the retrieved precipitation fields, obtained from the UW-NMS and the MM5 CRD's. This result demonstrates that significant differences (up to $10 \mathrm{~mm} / \mathrm{hr}$ ) may be found for any rain rate regime between the UW-NMS and the MM5 derived rainfall rates - despite their overall similar behavior.

\section{Conclusions}

This study has clearly demonstrated that: a), important differences may be found in cloud-radiation databases generated by different cloud resolving models adopting different bulk microphysical schemes - even when the models are used to simulate the same event(s) and all model simulations reproduce reasonably well the observed accumulated precipitation and rainfall patterns; and b), these CRD differences may produce significant differences in the retrieved rain rates. This problem has to be seriously tackled in order to produce global, reliable and consistent precipitation retrievals. However, it has been so far largely overlooked. This study is a first step towards that direction. In the future, we plan to consider additional case studies and cloud resolving models, so as to achieve more general conclusions and quantify the CRM-effect on rainfall retrieval uncertainties.

Acknowledgements. This study has been supported by the National Group for Prevention from Hydro-geological Hazards (GNDCI) of the Italian National Research Council (CNR), by the Italian Space Agency (ASI), the European Community Initiative INTERREG III B CADSES - RISK AWARE project, and the Greek-Italian collaboration project financed by the General Secretariat for Research and Technology.

Edited by: L. Ferraris

Reviewed by: anonymous referees 


\section{References}

Dietrich, S., Di Michele, S., Kotroni, V., Lagouvardos, K., Medaglia, C. M., Mugnai, A., Panegrossi, G., Smith, E. A., and Tripoli, G. J.: Comparing cloud microphysics and derived microwave signatures generated by different cloud resolving models, in: 5th Plinius Conference on Mediterranean Storms, edited by: Testud, J., Mugnai, A., and Santucci, J.-F., pp. 433-442, 2003.

Di Michele, S., Marzano, F. S., Mugnai, A., Tassa, A., and Poiares Baptista, J. P. V.: Physically-based statistical integration ofTRMM microwave measurements for precipitation profiling, Radio Sci., 38 (4), 8072-8090, 2003.

Di Michele, S., Tassa, A., Mugnai, A., Marzano, F. S., Bauer, P., and Poiares Baptista, J. P. V.: Bayesian Algorithm for Microwavebased Precipitation Retrieval: Description and application to TMI measurements over ocean, IEEE Trans. Geosci. Remote Sens., in press, 2005.

Dudhia, J.: A non-hydrostatic version of the Penn State/NCAR mesoscale model: validation tests and simulation of an Atlantic cyclone and cold front, Mon. Wea. Rev., 121, 1493-1513, 1993.

Kotroni, V. and Lagouvardos, K.: Precipitation forecast skill of different convective parameterization and microphysical schemes: application for the cold season over Greece, Geophys. Res. Lett., 108, 1977-1980, 2001.
Mugnai, A., Di Michele, S., Marzano, F. S., and Tassa, A.: Cloud-model based Bayesian techniques for precipitation profile retrieval from TRMM microwave sensors, in Proc. ECMWF/EuroTRMM Workshop on Assimilation of Clouds and Precipitation, ECMWF, Reading UK, pp. 323-345, 2001.

Panegrossi, G., Dietrich, S., Marzano, F. S., Mugnai, A., Smith, E. A., Xiang, X., Tripoli, G. J., Wang, P. K., and Poiares Baptista, J. P. V.: Use of cloud model microphysics for passive microwavebased precipitation retrieval: significance of consistency between model and measurement manifolds, J. Atmos. Sci., 55, 1644 1673, 1998.

Smith, E. A., Kummerow, C., and Mugnai, A.: The emergence of inversion-type profile algorithms for estimation of precipitation from satellite passive microwave measurements, Remote Sens. Rev., 11, 211-242, 1994.

Tripoli, G. J.: A nonhydrostatic model designed to simulate scale interaction, Mon. Wea. Rev., 120, 1342-1359, 1992.

Tripoli, G. J., Panegrossi, G., Mugnai, A., Dietrich, S., and Smith, E. A.: A numerical study of the Friuli, 1998 and the Genoa, 1992 floods, in: 2nd Plinius Conference on Mediterranean Storms, edited by: Mugnai, A., Guzzetti, F., and Roth, G., pp. 127-140, 2001. 